\title{
Discrete Event Simulation of a Specialty Outpatient Clinic to Improve Patient Flow
}

\section{Samantha Lynn Mangoni \& Xuanjing Li \\ University of Florida}

Faculty Mentor: Xuanjing Li, Department of Industrial and Systems Engineering

\begin{abstract}
The objective of this study was to test the validity and efficacy of Arena discrete-event simulations (DES) in modeling a specialty outpatient clinic, and to use the model to predict how the clinic could improve their patient flow. Real-life model inputs included the time that patients spent in each clinic process, patient arrival rates, and physician room schedules. Model outputs and feedback from clinical leadership validated the DES models. Then, modified DES models with different clinic room scheduling patterns and resource use tested the effect of changes. Analysis of the models revealed that adding two volunteers to escort patients in the morning and afternoon would decrease the queue time to see a physician by $33.9 \%$ and $65.2 \%$, respectively. The model results also suggested that there is not enough congestion in the clinic to warrant changing the clinic room scheduling. The results of the study support using DES in the modeling and analysis of specialty outpatient clinics to aid decision making.

Keywords: Arena Simulation, Discrete Event Simulation, Health Systems Engineering
\end{abstract}

\section{Introduction}

Dynamic computer-based simulation modeling enables users to observe the dynamic behavior of entities in a system or the overall system. The behavior of entities, or the entire system, may change in response to different initial conditions, such as resources or process times. Dynamic computer-based simulations utilize equations that represent the true system to control entities in response to various initial conditions.

Discrete-event simulation(s) (DES) is a type of computer-based simulation modeling that describes dynamical systems. One key characteristic of DES is that entities in the simulation have inconsequential behavior at all points between discrete time points (Meiss, 2007). In other words, DES represents the system as instantaneous events instead of continuous points; this is useful when simulating processes that depend on events and not continuous data, such as scheduling, resources, and capacity planning (Campbell, 2017).

DES models may improve their validity by giving the option of introducing randomness, as real-life systems have some degree of stochasticity. Randomizing the amount of time that entities spend in each state with probability distributions allows for randomness (Zhang, 2010). 
Although the results of a simulation model will likely be less accurate than the results of testing changes to a system in real life, DES provides a safe, cost-effective and time-effective way to study the response of the system to changes. For example, if a restaurant owner wanted to test the effect of decreasing the number of servers in real life, this may result in increased time for customers to receive their food. The cost could be customer dissatisfaction and/or customers choosing to dine elsewhere. If a restaurant owner wanted to vary the number of servers over several iterations, then they may have to do so over several evenings. With DES, the restaurant owner could vary the number of servers quickly in a model without affecting customer satisfaction. While there is the cost of time and effort to obtain data for and create a simulation model, this cost is relatively low for some systems in comparison to the cost of testing the changes in real life. In summary, processes may be simulated to minimize the risk of making decisions for system structure or flow. In fact, DES has various applications because of its ability to minimize risk; these applications include modeling supply chains, manufacturing and production, transportation planning and business processes (Tako, Robinson, 2012 ;Spieckermann, Stobbe, 2016; Chahar, Cheng, \& Pranoto, 2011; Leva, Sulis, Lellis, \& Amantea, 2019). DES has also been applied to various healthcare systems that focus on managing patient flow through improving processes, including patient scheduling, and resource usage (Hamrock, Paige, Parks, Scheulen, \& Levin, 2013; Medeiros, Hahn-Goldberg, Aleman, \& O’Connor, 2019).

DES may be especially useful for decision-making in healthcare systems engineering, as quality of patient care can be reduced if system changes are tested in real life. Even small changes in complex clinic processes can have cascading effects, such as shifting a bottleneck or changing wait times that could not be predicted without a simulation. With the dynamic, random, and quality of care focused nature of the clinic system, as well as the promise that DES has shown in other industries, DES was the method chosen to investigate the clinic flow of a specialty clinic. The aim of this study was to determine the validity and efficacy of DES for modeling a specialty outpatient clinic at the Veterans Affairs (VA) Hospital in Gainesville, Florida.

The clinic modeled in the VA was the specialty outpatient clinic, a multi-specialty clinic that offers clinical services to eligible veterans. Clinical leadership were not satisfied with the clinic utilization rate and sought a way to improve patient flow; they wanted to increase the number of patients seen throughout the week. However, the clinical leadership was unsure of what changes 
would be effective. DES enabled the clinic to study how they could change scheduling and resource usage. Analysis of the models revealed that adding two volunteers to escort patients in the morning and afternoon would decrease the queue time to see a physician by $33.9 \%$ and $65.2 \%$, respectively. The model results also suggested that there is not enough congestion in the clinic to warrant changing the clinic scheduling from fixed room scheduling to unassigned room scheduling. The results of the study support using DES in the modeling and analysis of specialty outpatient clinics to support decisions. The following paper outlines the steps taken to develop, validate and analyze the DES of a specialty outpatient clinic.

\section{Methods}

Arena simulation was the software used to develop the DES models. Arena is a simulation software based on the SIMAN simulation language with object-oriented and hierarchical elements (Takus, profozich, 1997). Arena was originally developed by Systems Modelling Corporation, before being acquired by Rockwell Automation headquartered in Milwaukee, WI (Martin, 2000). Several steps were taken to develop clinic models: input analysis, initial model development, model validation, modified model development and model analysis.

\section{Input Analysis}

Real data and inputs were necessary for the model's development to make the DES representative of real-life conditions. Touring the specialty clinic floor and coordinating meetings with clinic staff to gather their insight on the clinic flow helped develop a realistic and relevant clinic model. Discussions with clinic staff drew attention to key problems that the clinic faced and indicated potential solutions.

The VA collected raw data from several weekdays, as the appointment schedule for each physician varied day-to-day. However, the model only used Friday data for simplicity and because clinic staff observed that Friday had the most room for improvement due to the clinic's low room utilization rate and high patient wait times. The data collected included: patient checkin and check-out time, time for physicians to escort patients to check-out area, time it takes for patients to check in and check out, patient time in vital rooms, physician time with patients, and physician room schedules. 


\section{Initial Model Development}

A basic clinic flow map would serve as the basis for the specialty clinic model (Figure 1). The model included only processes that had a relatively significant impact on patient flow (Figure 2). For example, the model excluded walk-in patients because the number of walk-in patients was low and would have added an unnecessary layer of complexity to the model.

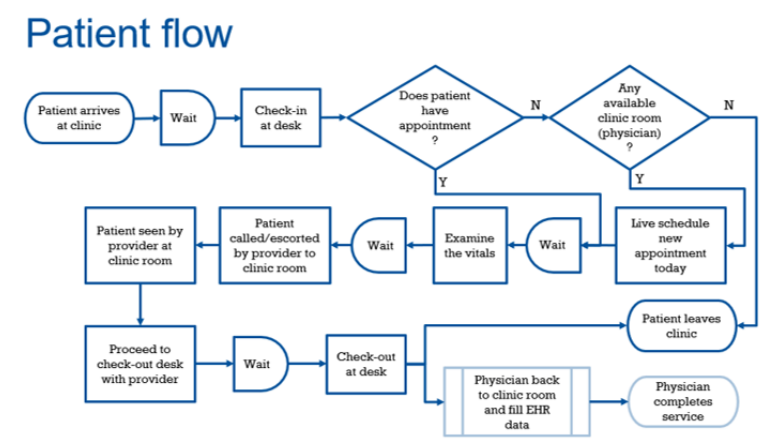

Figure 1. Gainesville VA specialty clinic flow map developed for the DES model

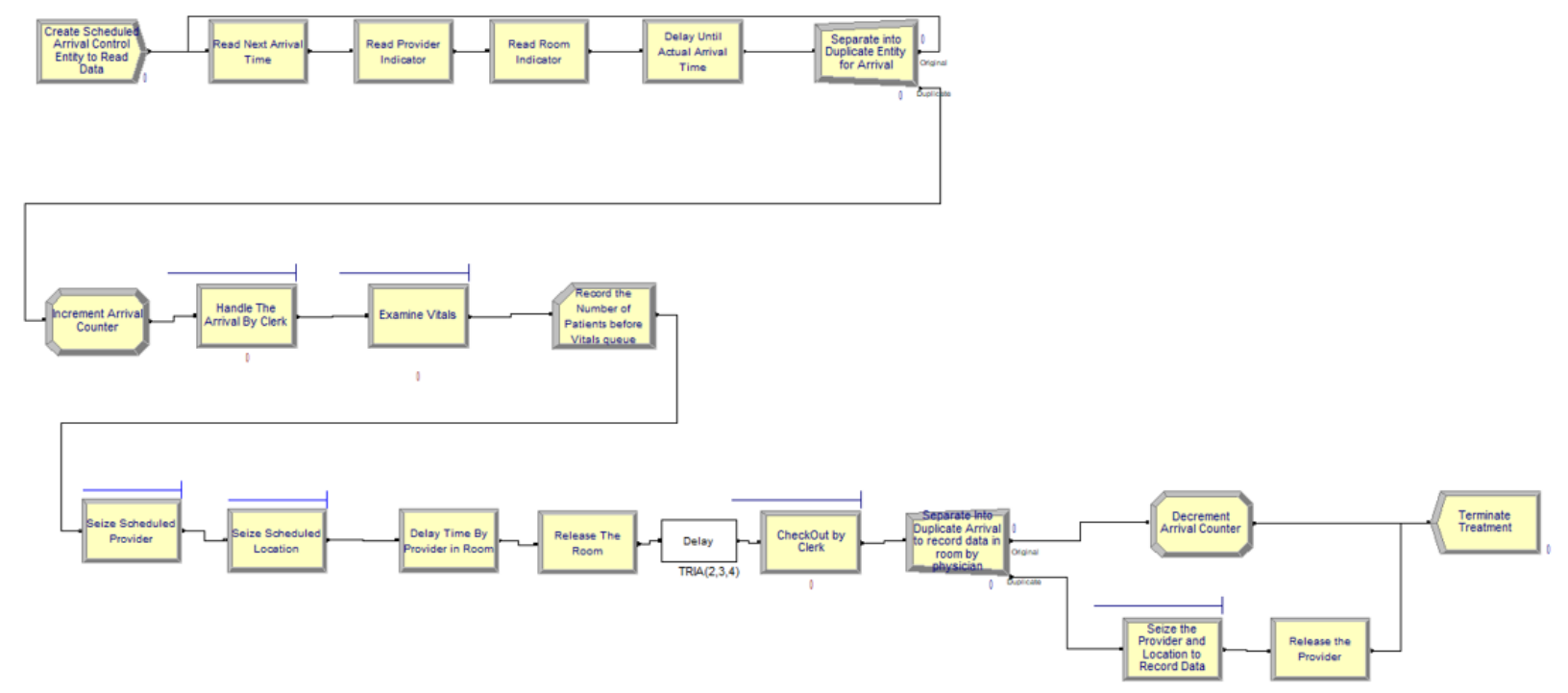

Figure 2. Initial VA clinic simulation model in Arena.

A total of five clerks facilitated patient check-in and check-out. The model tracked time under the simulation clock variable in Arena, TNOW, in minutes. Zero minutes represented 8:00 AM, while 480 minutes represented 4:00 PM. The specialty clinic data showed that patient arrivals were much more frequent in the morning than in the afternoon on Fridays. As such, a model representing the entire clinic day became two models, a morning and afternoon clinic 
model; this allowed the morning and afternoon clinic resource use and scheduling to have separate evaluations. The only differences between the all-day and separate models were the data files the DES processed and the model's stopping rule. The morning model stopped simulating when TNOW was greater than or equal to 240 minutes and the number of patients in the clinic simulation was zero. The afternoon clinic stopped simulating when TNOW was greater than or equal to 480 minutes and the number of patients in the clinic simulation was zero. Arena reported results as a time average for each process (e.g., average time for a physician to seize a room). These morning and afternoon clinic models served as the basis for all models. Additional details on each simulation module are in the Appendix, Table 3.

\section{Model Validation}

Equation (1) gave the real and simulated all-day, morning and afternoon clinic utilization rates.

$$
\text { Utilization }=\frac{\Sigma \text { appointment length }}{\Sigma \text { clinic hours }} \times 100 \%
$$

To further validate the model, the results of a simulated clinic with exponential patient interarrival and the results of the morning and afternoon models were compared. Clinical leadership reviewed the model and gave feedback on the processes and wait times.

\section{Modified Model Development}

Several modified models investigated the effects of resource and scheduling changes with recommendations from clinic staff and the results of earlier models (Table 1). One recommendation from clinic staff was to develop a model with unassigned room scheduling. In the present, physicians followed a fixed room schedule where physicians had assigned clinic rooms for their appointments. Physicians were unable to use empty clinic rooms, which could have caused longer wait times if their rooms were still in use from other physician appointments. One possible reason that rooms would have still been in use is because physicians completed post-visit documents in their clinic room, potentially overlapping with the next physicians' time. In response, some models had separate office spaces for physicians to complete post-visit documents. An unassigned room model was also developed where physicians could occupy any available room. Another issue presented by clinic staff was that physicians needed to escort patients to the check-out desk after their appointment, which sometimes prevented the physician from seeing the following patient on time. An alternative method discussed was having a 
volunteer escort patient to the check-out desk. A summary of the models can also be found in

Table 2.

Table 1. Modified Morning and Afternoon Clinic Models

\begin{tabular}{|c|c|c|}
\hline $\begin{array}{l}\text { Model Time } \\
\text { (AM, PM, or } \\
\text { AM \& PM) }\end{array}$ & $\begin{array}{l}\text { Model } \\
\text { Identifier }\end{array}$ & Model Description \\
\hline AM \& PM & $\begin{array}{l}1(\mathrm{AM}) \\
2(\mathrm{PM})\end{array}$ & $\begin{array}{l}\text { Physicians were no longer assigned rooms as they were in a fixed room schedule. } \\
\text { Instead, two rooms remained fixed, while } 11 \text { rooms in the AM and four rooms in the } \\
\text { PM model rotated. The two rooms remained fixed because they contained specialized } \\
\text { pacer medical equipment on several carts that could not be easily removed from the } \\
\text { room. }\end{array}$ \\
\hline $\mathrm{AM}$ & 3 & $\begin{array}{l}\text { Same as model 1, except nine unassigned rooms were available instead of } 11 \text {. Two } \\
\text { other rooms remained fixed. }\end{array}$ \\
\hline $\mathrm{PM}$ & 4 & $\begin{array}{l}\text { Same as model 2, except three unassigned rooms were available instead of four. Two } \\
\text { other rooms remained fixed. }\end{array}$ \\
\hline $\mathrm{AM}$ & 5 & $\begin{array}{l}\text { Same as model 1, except eight unassigned rooms were available instead of } 11 . \text { Two } \\
\text { other rooms remained fixed. }\end{array}$ \\
\hline AM \& PM & $\begin{array}{l}6(\mathrm{AM}) \\
7(\mathrm{PM})\end{array}$ & $\begin{array}{l}\text { Same as model } 1 \text { and model } 2 \text {, except the model was congested with an increased } \\
\text { number of patients. The patients were all walk-in patients with an interarrival rate } \\
\text { modeled by an exponential distribution. }\end{array}$ \\
\hline $\mathrm{AM}$ & 8 & $\begin{array}{l}\text { Same as model } 5 \text {, except two volunteers were also introduced to the model to escort } \\
\text { patients to the check-out desk. This allowed physicians to be released to complete } \\
\text { their post-visit paperwork immediately after seeing patients. }\end{array}$ \\
\hline $\mathrm{AM}$ & 9 & $\begin{array}{l}\text { Same as model } 8 \text {, except an office space was also added to the model for physicians to } \\
\text { complete their post-visit paperwork in. The office space had an infinite capacity and } \\
\text { prevented physicians from occupying physician rooms once physicians were done } \\
\text { seeing patients. }\end{array}$ \\
\hline AM \& PM & $\begin{array}{l}10(\mathrm{AM}) \\
11(\mathrm{PM})\end{array}$ & $\begin{array}{l}\text { Same as initial AM and PM model, except one volunteer is used to escort patients to } \\
\text { the check-out desk instead of physicians escorting patients to the check-out desk. }\end{array}$ \\
\hline $\mathrm{AM} \& \mathrm{PM}$ & $\begin{array}{l}12(\mathrm{AM}) \\
13(\mathrm{PM})\end{array}$ & Same as models 10 and 11 , except two volunteers are used instead of one. \\
\hline $\mathrm{AM}$ & 14 & $\begin{array}{l}\text { Same as initial AM model, except an office space was also added to the model for } \\
\text { physicians to complete their post-visit paperwork in. }\end{array}$ \\
\hline $\mathrm{PM}$ & 15 & $\begin{array}{l}\text { Same as model } 2 \text {, except one volunteer escorted patients to the check-out desk and an } \\
\text { office space was introduced to the model for physicians to complete their post-visit } \\
\text { paperwork in. }\end{array}$ \\
\hline $\mathrm{PM}$ & 16 & $\begin{array}{l}\text { Same as initial PM model, except an office space was introduced to the model for } \\
\text { physicians to complete their post-visit paperwork in. }\end{array}$ \\
\hline $\mathrm{AM} \& \mathrm{PM}$ & $\begin{array}{l}17(\mathrm{AM}) \\
18(\mathrm{PM})\end{array}$ & $\begin{array}{l}\text { Same as initial AM and PM model, except the model was congested with an increased } \\
\text { number of patients. The patients were all walk-in patients with an interarrival rate } \\
\text { modeled by an exponential distribution } \mathrm{e}^{2} \text {. }\end{array}$ \\
\hline
\end{tabular}


Table 2. Summary of Modified Morning and Afternoon Clinic Models

\begin{tabular}{|l|l|}
\hline Model Number & Model Summary \\
\hline 1 & AM, 2 fixed rooms, 11 unassigned rooms \\
\hline 2 & PM, 2 fixed rooms, 4 unassigned rooms \\
\hline 3 & AM, 2 fixed rooms, 9 unassigned rooms (2 reduced) \\
\hline 4 & PM, 2 fixed rooms, 3 unassigned rooms (1 reduced) \\
\hline 5 & AM, 2 fixed rooms, 8 unassigned rooms (3 reduced) \\
\hline 6 & $\begin{array}{l}\text { AM, 2 fixed rooms, 11 unassigned rooms, exponential patient } \\
\text { interarrival rate }\end{array}$ \\
\hline 7 & $\begin{array}{l}\text { PM, 2 fixed rooms, 4 unassigned rooms, exponential patient } \\
\text { interarrival rate }\end{array}$ \\
\hline 8 & $\begin{array}{l}\text { AM, 2 fixed rooms, 8 unassigned rooms (3 reduced), 2 } \\
\text { volunteers }\end{array}$ \\
\hline 9 & $\begin{array}{l}\text { AM, 2 fixed rooms, 8 unassigned rooms (3 reduced), 2 } \\
\text { volunteers, office space }\end{array}$ \\
\hline 10 & AM, 13 fixed rooms, 1 volunteer \\
\hline 11 & PM, 6 fixed rooms, 1volunteer \\
\hline 12 & AM, 13 fixed rooms, 2 volunteers \\
\hline 13 & PM, 6 fixed rooms, 2 volunteers \\
\hline 14 & AM, 13 fixed rooms, office space \\
\hline 15 & $\begin{array}{l}\text { PM, 2 fixed rooms, 4 unassigned rooms, 1 volunteer, office } \\
\text { space }\end{array}$ \\
\hline 16 & PM, 6 fixed rooms, office space \\
\hline AM, 13 fixed rooms, exponential patient interarrival rate \\
\hline
\end{tabular}




\section{Results}

\section{Initial Morning Simulation Results}

The results of the morning clinic model indicated that the longest wait time occurred when patients waited to see a physician (Figure 3). The results further indicated that there was almost zero wait for physicians to seize their scheduled room to see patients, or to seize their room to complete post-visit documents.

\section{Initial Afternoon Simulation Results}

The results of the afternoon clinic model were similar to the morning clinic model, but smaller in magnitude since the morning clinic had about 3.6 times more patients than the afternoon clinic. The longest queue would occur when patients were waiting for their physician (Figure 4). The results also indicated that there was almost no wait for physicians to seize their scheduled room to see patients, or to seize their room to complete post-visit documents.

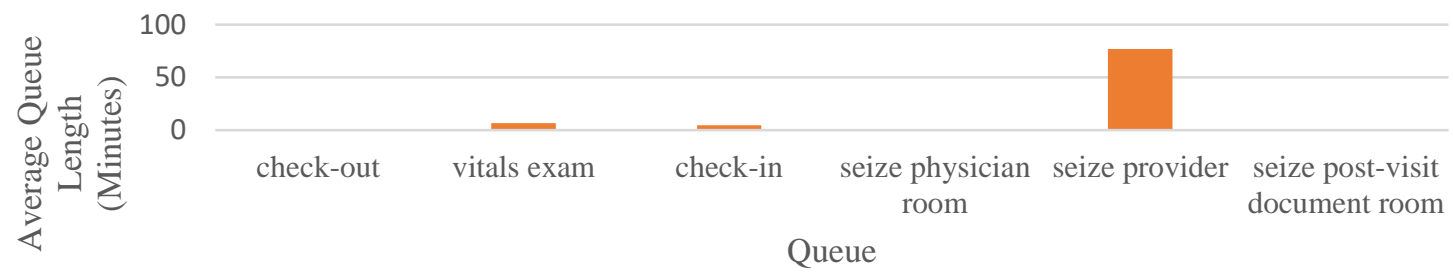

Figure 3. Initial morning simulation model queue lengths

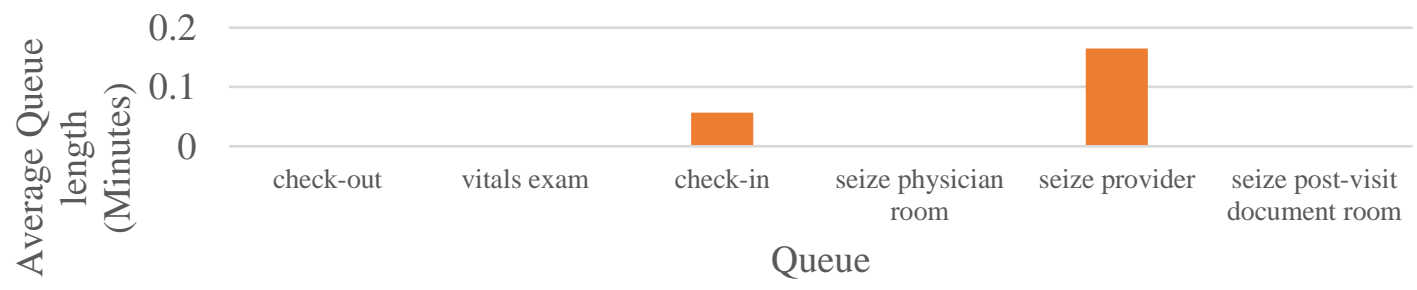

Figure 4. Initial afternoon simulation model queue lengths

\section{Model Validation Results}

The average utilization rate of clinic rooms in the afternoon and all-day data was $34.7 \%$ and $29.1 \%$, respectively. The average utilization rate in the simulated afternoon and all-day clinic was $32.38 \%$ and $18.32 \%$, respectively. The utilization rates were within a $11 \%$ margin of error. The sensitivity of the models to exponential patient interarrival further supported the validity of 
the models because predictable results occurred: all queues increased, and the bottleneck of the clinic remained the same. Medical leadership also reviewed the model processes and delay times.

\section{Modified AM Model Results}

The use of an unassigned room schedule decreased provider wait time by an average of 5.11 minutes (Figure 5). When three of the 11 rooms were removed in a model with an unassigned room schedule, all queues began to rise. However, the removal of two rooms had no effect on patient wait times (Figure 5). When two volunteers were introduced to a clinic with an unassigned room schedule and nine of the 11 rooms, the provider wait time decreased by an average of 26.6 minutes, or 35.0\%, relative to the same model with no volunteers (Figure 5). When exponential patient interarrival congested a fixed schedule model and unassigned room schedule model, provider wait time was an average of 29.9 minutes or $42.3 \%$ lower in the unassigned room schedule model (Figure 6). When one volunteer was introduced to a fixed room model, the provider wait time decreased by an average of 26.08 minutes, or $33.9 \%$, relative to the same model with no volunteers (Figure 7). The queue length to seize one volunteer in a fixed room model was 12.9 minutes on average (Figure 7). When two volunteers were used in a fixed room model, the queue to seize a volunteer decreased on average from 12.9 minutes to 0.38 minutes and all other queues remained the same (Figure 7). There was no observed difference in wait times when an office space was introduced to any morning clinic model (Figure 5 and Figure 7).

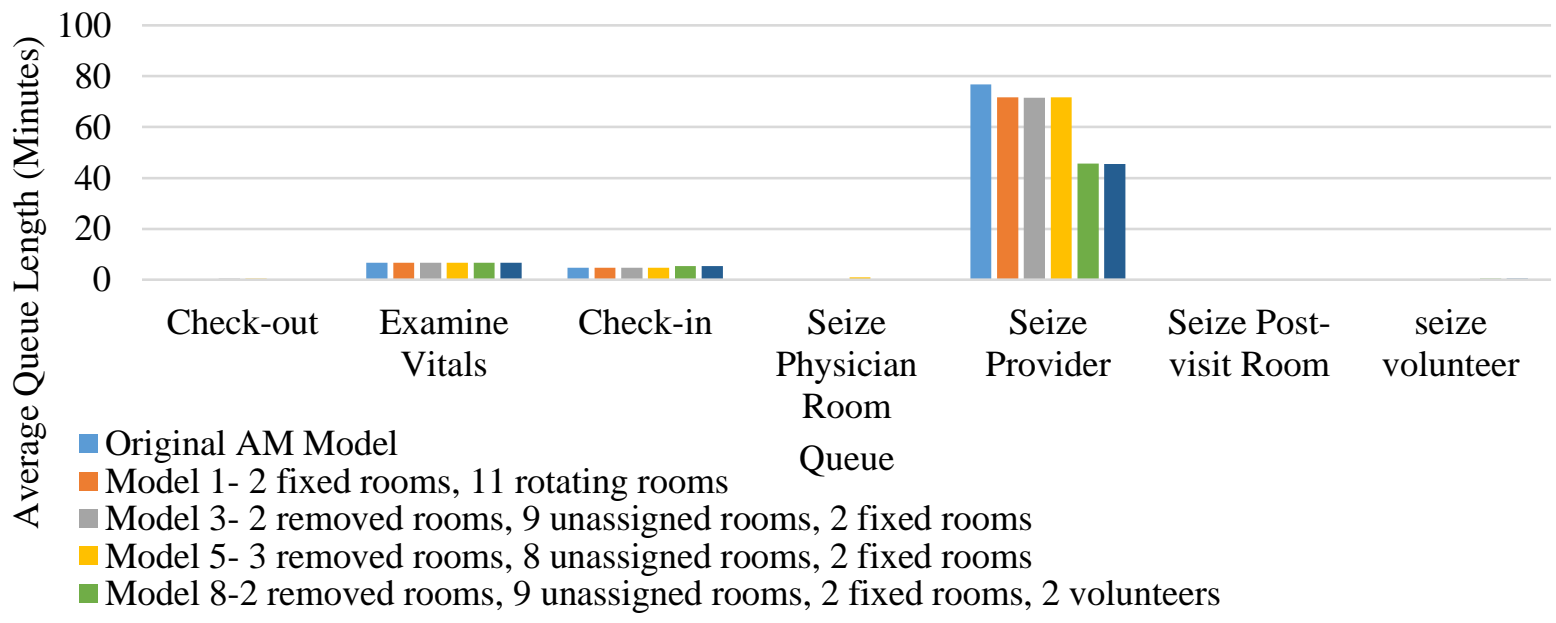


Figure 5. Comparison between morning unassigned room schedule clinics and initial morning model results

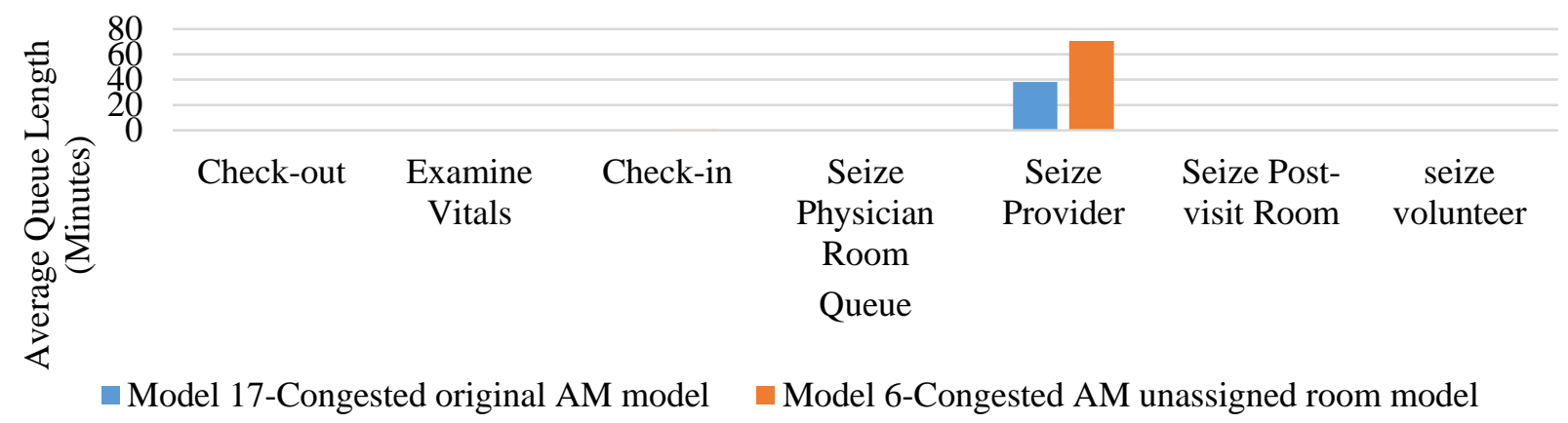

Figure 6. Comparison between morning fixed room congestion results and morning unassigned room congestion results

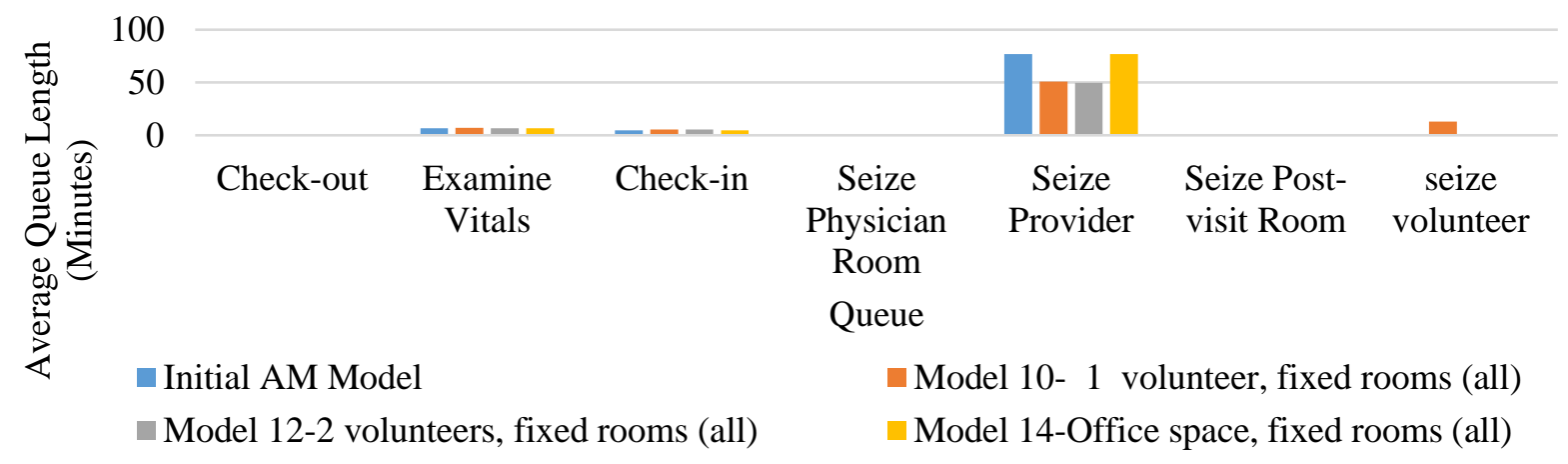

Figure 7. Comparison between morning fixed room schedule clinics and initial morning model results.

\section{Modified PM Model Results}

The use of an unassigned room schedule decreased provider wait time by an average of 0.49 minutes (Figure 8). The removal of one room had no effect on patient wait times (Figure 8). When one volunteer and an office space were introduced to a clinic with an unassigned room schedule, the provider wait time increased by an average of 0.46 minutes compared to the initial model (Figure 8). When exponential patient interarrival congested a fixed schedule model and an unassigned room schedule model, provider wait time was an average of 132 minutes, or 105\%, lower in the unassigned room schedule model (Figure 9). The queue to seize a room was also an average of 6.19 minutes higher in a congested clinic with a fixed room schedule than a congested clinic with an unassigned room schedule (Figure 9). When one volunteer was introduced to a fixed room model, provider wait time decreased by an average of 0.06 minutes, or $37.6 \%$, relative to the same model without a volunteer (Figure 10). The queue to seize a volunteer was an average of 0.57 minutes long in a fixed room model (Figure 10). When two volunteers were 
used in a fixed room model, there was no queue to seize a volunteer and provider wait time decreased 0.10 minutes, or $65.2 \%$, on average relative to the same model without volunteers. There was no observed difference in wait times when an office space was introduced to any model (Figure 8 and Figure 10).

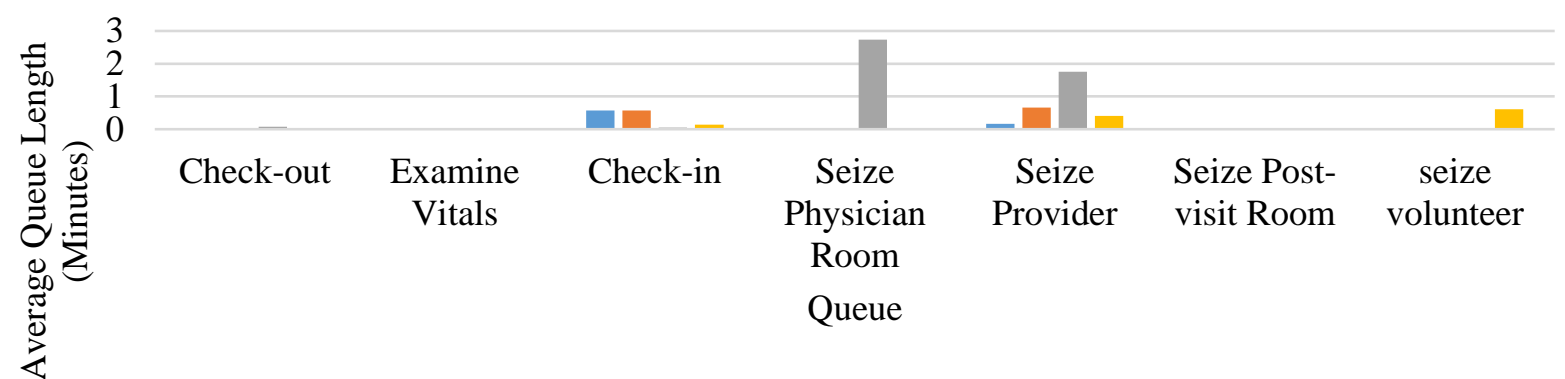

- Initial PM model

- Model 2-2 fixed rooms, 4 unassigned rooms

Model 4-2 fixed rooms, 3 unassigned rooms

$\square$ Model 15-2 fixed rooms, 4 unassigned rooms, 1 volunteer, 1 office space

Figure 8. Comparison between afternoon unassigned room schedule clinics and initial afternoon model results

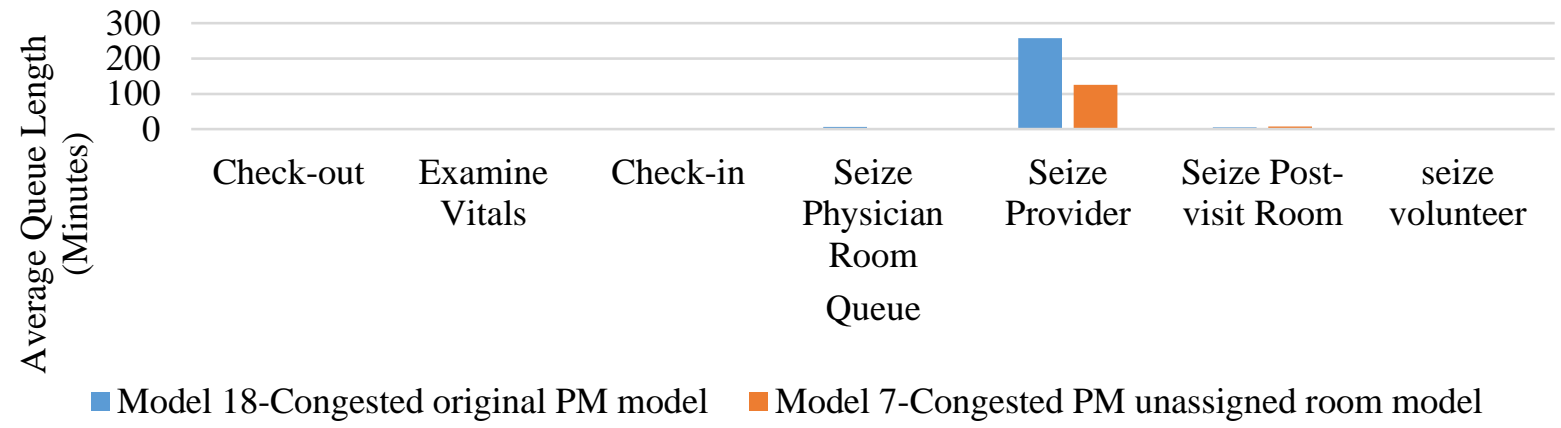

Figure 9. Comparison between afternoon fixed room congestion results and afternoon unassigned room congestion results 


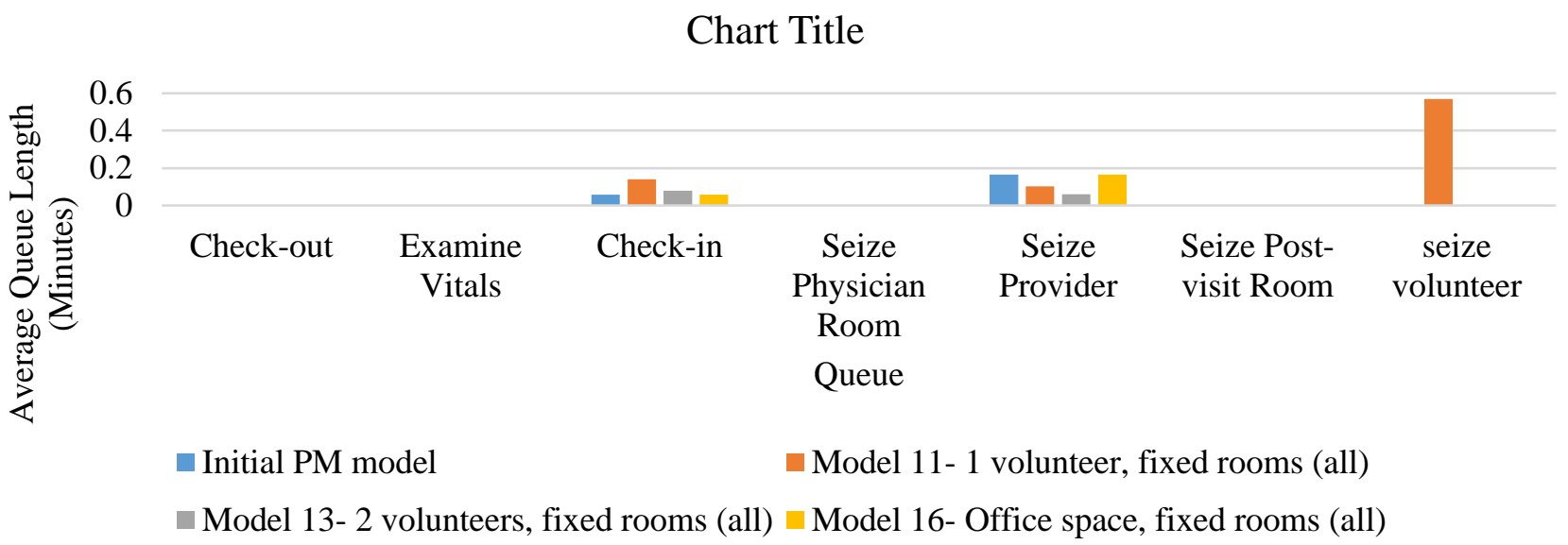

Figure 10. Comparison between afternoon fixed room schedule clinics and initial afternoon model results

\section{Discussion}

The results of the initial morning and afternoon clinic simulations suggest that physicians are the bottleneck of the clinic, as the wait time to see a physician was much longer than any other clinic wait time. With current patient flow in the Friday clinic, the wait time for physicians to seize a room to see patients or complete paperwork was smaller than one minute in the morning and afternoon clinic. As a result, changes to room scheduling and increasing room availability did not make a large difference to any of the queues in either model. When an influx of patients arrived at the unassigned and fixed room scheduling models, the model with unassigned room scheduling showed decreases in all queue lengths compared to the model with fixed room scheduling in both the afternoon and morning clinic. Thus, the clinic should not change their room scheduling method unless patient arrival rates increase, such as exponential patient interarrival time.

Moreover, there was about no difference in wait times between a morning model with nine unassigned rooms and eleven unassigned rooms, indicating that up to two rooms could be removed from the morning clinic if there was an unassigned room schedule. Similarly, in the afternoon model no difference in wait times occurred when there was one less unassigned room in the clinic. One potential use for these clinic rooms was to use them as an office space for physicians to complete post-visit documents instead of completing the documents in clinic rooms. However, introducing the office space made no difference in any of the queue lengths in the morning or afternoon model; this is likely because clinic room availability was not constraining patient flow. Other uses could be determined by the hospital or clinic staff. 
Adding volunteers to the models expectedly reduced the wait time to see a physician because there was one less process constraining physician time. In other words, reducing the burden on the bottleneck resource may be effective in improving clinic performance. Adding two volunteers to the fixed room morning model reduced the wait time for volunteers to zero minutes and the queue to seize a physician decreased by an average of about 13 minutes. Adding one volunteer to the afternoon clinic had similar results, as there was also no wait time for volunteers and a decrease in queue lengths. These results support that two volunteers should be added to the morning clinic and one volunteer should be added to the afternoon clinic to improve patient flow.

\section{Conclusion}

DES models evaluated the clinic processes and identified the bottleneck of the clinic. Clinic leadership could observe clinic performance with changes to the clinic structure without interrupting the clinic operations, or the time and cost of physically testing changes to the clinic. The specialty clinic will be able to apply these results in making decisions about resource allocation, scheduling, and clinic layout. The changes and decisions made by clinics based on DES results do not have to come directly from the model's intended output. For example, the study on adding volunteers to the model revealed that physicians escorting patients was constraining patient flow. However, if the clinic did not want to depend on volunteers to escort patients as suggested in the model, they could study alternative models. For example, a model could adjust the clinic layout and place the check-out area closer to the clinic rooms to decrease the amount of time that physicians spend escorting patients. Overall, the results of this study support that DES shows promise for supporting decision-making in clinics.

\section{Limitations}

One limitation of using DES is that event simulation is a simplified presentation of reality that does not entirely account for the unpredictable nature of real-life systems. The results of the simulation may not apply under unexpected events, such as a natural disaster or other event that significantly increases patient arrival past the congested model arrival rate. Randomness could also come from the behavior of clinic staff, as productivity might fluctuate throughout the day. The model assumed that productivity did not fluctuate with time. Another limitation of DES is that it relies heavily on real-life data that may be expensive and time-consuming to acquire. If real data is not obtained, it may be difficult to develop a reliable model that accurately represents the clinic flow. One important note is the lack of standard deviation on any of the wait times. 
Although there is error associated with the data, the sample size was not high enough for Arena to make a normal distribution that would allow Arena to automatically report the halfwidth. Thus, no standard deviation was reported.

\section{Future Work}

Other than the congested model, the simulation models assumed that there were no walk-in patients. Future research could investigate the effect of walk-in patients on patient flow. One possible research area would be allocating an extra clinic room just for walk-in patients. The current model also assumed that the productivity of clinic staff is constant. While, in real life, productivity may fluctuate with time or patient arrival rate. Adjusting the DES model delays to account for fluctuations in productivity of clinic staff may improve the accuracy of the model. Data on productivity could be obtained from psychological studies. This simulation, or other DES models, could also be used by the clinic administration staff to decide alternative uses for the unnecessary room(s) in the morning and afternoon clinic. Future work could also extend outside of the medical field, as studies could investigate the use of DES in decision making for resource allocation and facility design in clothing stores, grocery stores, restaurants, and more. To ensure that Arena does calculate a standard deviation, future work should also include a tally module. If no tally module is included, then replications should increase to have Arena automatically report the halfwidth of average patient wait times between replications. 


\section{Appendix}

Table 3. Simulation Functions

\begin{tabular}{|c|c|}
\hline Process & Purpose \\
\hline $\begin{array}{l}\text { Create scheduled arrival } \\
\text { control entity to read } \\
\text { data }\end{array}$ & Starts simulation/ opens clinic at 8:00 AM. \\
\hline Read next arrival time & $\begin{array}{l}\text { Reads arrival time of patients from Excel spreadsheet and stores time under variable } \\
\text { ArrivalTime }\end{array}$ \\
\hline Read provider indicator & $\begin{array}{l}\text { Reads entity provider identifier from Excel spreadsheet and stores under variable } \\
\text { ProviderIndicator }\end{array}$ \\
\hline Read room indicator & $\begin{array}{l}\text { Reads provider room identifier from Excel spreadsheet and stores under variable } \\
\text { RoomIndicator. }\end{array}$ \\
\hline $\begin{array}{l}\text { Delay until actual } \\
\text { arrival time }\end{array}$ & Prevents patient from arriving in clinic until appointment time \\
\hline $\begin{array}{l}\text { Increment arrival } \\
\text { counter }\end{array}$ & Increases tally number of patients in clinic by one each time a patient arrives \\
\hline $\begin{array}{l}\text { Handle the arrival by } \\
\text { clerk }\end{array}$ & $\begin{array}{l}\text { Simulates patient check-in with triangular distribution. Maximum, minimum, and mean time } \\
\text { spent at check-in were obtained from raw data. }\end{array}$ \\
\hline Examine vitals & $\begin{array}{l}\text { Simulates patients getting their vitals checked in vitals room with triangular distribution. } \\
\text { Maximum, minimum, and mean time spent at check-in were obtained from raw data. }\end{array}$ \\
\hline $\begin{array}{l}\text { Record the number of } \\
\text { patients before vitals } \\
\text { queue }\end{array}$ & Keeps track of vitals queue for model analysis. \\
\hline $\begin{array}{l}\text { Seize scheduled } \\
\text { provider }\end{array}$ & Assigned provider is seized by patient. \\
\hline $\begin{array}{l}\text { Seize scheduled } \\
\text { location }\end{array}$ & Assigned room is seized by patient and provider. \\
\hline $\begin{array}{l}\text { Delay time by provider } \\
\text { in room }\end{array}$ & $\begin{array}{l}\text { Simulates time it takes for physician to see patient with triangular distribution. Maximum, } \\
\text { minimum, and mean time spent at check-in were obtained by calculating the utilization rate of } \\
\text { the clinic rooms and modifying the distribution until the utilization rate was achieved. }\end{array}$ \\
\hline Check-out by clerk & $\begin{array}{l}\text { Simulates patient check-out with triangular distribution. Maximum, minimum, and mean time } \\
\text { spent at check-in were obtained from raw data. }\end{array}$ \\
\hline $\begin{array}{l}\text { Separate into duplicate } \\
\text { arrival to record data in } \\
\text { room by physician }\end{array}$ & Allows patient to leave clinic while provider is doing post-visit paperwork. \\
\hline $\begin{array}{l}\text { Decrement arrival } \\
\text { counter }\end{array}$ & $\begin{array}{l}\text { Decreases tally number of patients in clinic by one each time a patient leaves. When this tally } \\
\text { number is zero, the simulation has met one of its terminating condition. }\end{array}$ \\
\hline $\begin{array}{l}\text { Seize the provider and } \\
\text { location to record data }\end{array}$ & Provider seizes room and records post-visit data. \\
\hline Release the provider & Provider is free to see another patient \\
\hline Terminate treatment & Allows the clinic to stop accepting patients at 4:00 PM \\
\hline
\end{tabular}




\section{References}

Chahar, K., Cheng, C., \& Pranoto, Y. (2011). Strategic crew planning tool in railroad: A discrete event simulation. Proceedings of the 2011 Winter Simulation Conference (WSC). doi:10.1109/wsc.2011.6148062

Hamrock, E., Paige, K., Parks, J., Scheulen, J., \& Levin, S. (2013). Discrete Event Simulation for Healthcare Organizations: A Tool for Decision Making. Journal of Healthcare Management, 58(2), 110-124. doi:10.1097/00115514-201303000-00007

Leva, A. D., Sulis, E., Lellis, A. D., \& Amantea, I. A. (2019). Business Process Analysis and Change Management: The Role of Material Resource Planning and Discrete-Event Simulation. Exploring Digital Ecosystems Lecture Notes in Information Systems and Organisation, 211-221. doi:10.1007/978-3-030-23665-6_15

Martin, R. (2000, April 28). Rockwell Automation Acquires Systems Modeling Corporation. Retrieved July 28, 2020, from https://www.gartner.com/en/documents/1349942/rockwell-automation-acquiressystems-modeling-corporation

MathWorks. (Will Campbell). (2017). Understanding Discrete-Event Simulation [Webinar]. https://www.mathworks.com/videos/series/understanding-discrete-event-simulation.html

Medeiros, D. T., Hahn-Goldberg, S., Aleman, D. M., \& O’Connor, E. (2019). Planning Capacity for Mental Health and Addiction Services in the Emergency Department: A Discrete-Event Simulation Approach. Journal of Healthcare Engineering, 2019, 1-11. doi:10.1155/2019/8973515

Meiss, J. (2007, February 09). Dynamical systems. Retrieved March 24, 2020, from http://www.scholarpedia.org/article/Dynamical_systems

Profozich, D., \& Takus, D. Arena Software Tutorial. Systems Modeling Corporation. http://www.just.edu.jo/ mzali/courses/Winter15/Cis330/files/0541.PDF

Spieckermann, S., \& Stobbe, M. (2016). Applications of Discrete-Event Simulation in the Chemical Industry. In USE CASES OF DISCRETE EVENT SIMULATION: Appliance and research (pp. 309319). Heidelberg, Germany: Springer, Berlin, Heidelberg. doi:https://doi.org/10.1007/978-3-64228777-0_14

Tako, A. A., \& Robinson, S. (2012). The application of discrete event simulation and system dynamics in the logistics and supply chain context. Decision Support Systems, 52(4), 802-815. doi:10.1016/j.dss.2011.11.015

Zhang, P. (2010). Industrial control system simulation routines. Advanced Industrial Control Technology, 781-810. doi:10.1016/b978-1-4377-7807-6.10019- 